\title{
Editorial
}

\section{Virtually In-Person}

Welcome to the latest issue of Information Polity! We are writing this Editorial as we reach the point at which the COVID-19 pandemic has been with us for over 18 months. In this period, we have grown accustomed to online meetings in the workplace and find that large parts of our daily lives are conducted and configured digitally. For those of us who are academics, this has involved extensive online teaching and participation in online workshops and conferences. As eGovernment scholars, we are well versed in the challenges of delivering online services and the many pitfalls posed by issues like: privacy, digital inclusion, digital and data literacy, not to mention issues associated with algorithmic accountability, the commercialisation of public data and the transformation of state apparatus.

In recent months, there have been new opportunities to attend events in-person and this has reawakened our need to interact physically with our peers. Many of these events have been 'hybrid' in that they have been simultaneously online and in-person, and necessarily involve another layer of technical complexity if they are to function effectively. Whilst during the pandemic it has been possible to undertake much of our work online, it is evident that this has not supplanted the need for physical interaction and engagement. Over the last few months we have participated in a number of in-person (hybrid) events, albeit with social distancing measures in place, and it is clearly observable how important such events are. There has been a rekindled enthusiasm to engage with ideas, to discuss new and future research, to help scholars navigate the research environment, and to explore critical issues. Numerous colleagues have commented on how rewarding these events have been, and how they feel reinvigorated and reenergised. This is not to say, that much of this work could not have been done digitally, but that there is some often undefined added value from undertaking these activities in-person and with other people. This seems especially pertinent for those engaged in collaborative research and for those starting out on their academic journey. Participating in these meetings has somehow felt like an illicit activity, as though we are engaging in something subversive - the physical process of knowledge sharing, creation and networking - when we should all be busy with our online teaching and meetings.

Whilst it is clear that there are significant benefits to meeting in-person there is a strong sense that the 'new' digital methods for meeting and interacting that we have become accustomed to over the last 18 months are likely to endure, because they offer a range of potential advantages, beyond those associated with restricting the spread of the COVID-19 virus. There are notable efficiencies and cost savings for employers in having their staff work online. Staff are able to use their own computing equipment in their own homes, which creates costs savings in the heating and lighting of large buildings and facilities. Universities are able to simultaneously teach more students from more diverse locations, which in turn offers up new and enhanced income streams. There is also an opportunity to reduce the amount of time staff spend travelling to (international) meetings, as well as the cost associated with travelling to and staying in these locations. For these reasons, digital meetings are perceived to be cost efficient and effective. There is also a further compelling environmental argument about reducing national and international travel in order to reduce harmful emissions and to make a positive contribution to the climate change agenda. The dilemma - of whether to meet in-person or virtually - is likely to be with us 
for many years and is likely to impact the way we work and the outcomes of our work effort. Of course, what will happen in-practice is that we'll take a blended approach, where we 'hand-pick' those meetings, workshops and conferences, that we attend in person and those we attend virtually. This will be aided by institutional and professional prompts about how to navigate this landscape.

This edition of Information Polity is a Special Issue dedicated to understanding and exploring the relationship between 'social media and government'. This topic is of contemporary significance as it relates to how eGovernment is understood, practiced and experienced - and there is absolutely no doubt about the increasing use of social media for public service provision, the formation of public policy and for the functioning of our democratic and political systems. We would wholeheartedly like to thank the Guest Editors for doing such a wonderful job in assembling the articles presented here. This body of work represents an important marker for future research, as well as capturing what is currently known about the topic area.

You may be reading this edition of Information Polity virtually online or via a physically printed hard copy. Whichever medium it is we hope you enjoy it contents!

\section{Editors-in-Chief}

Professor Albert Meijer

Professor William Webster 